\title{
A Specific Autistic Trait that Modulates Visuospatial Illusion Susceptibility
}

\author{
Elizabeth Walter, \\ Department of Psychology and Institute of Neuroscience, University of Oregon, Eugene, OR \\ 97403-1227, USA
}

Paul Dassonville, and Department of Psychology and Institute of Neuroscience, University of Oregon, Eugene, OR 97403-1227, USA, e-mail:prd@uoregon.edu

\author{
Tiana M. Bochsler \\ Robert D. Clark Honors College and Department of Psychology, University of Oregon, Eugene, OR, \\ USA
}

\begin{abstract}
Although several accounts of autism have predicted that the disorder should be associated with a decreased susceptibility to visual illusions, previous experimental results have been mixed. This study examined whether a link between autism and illusion susceptibility can be more convincingly demonstrated by assessing the relationships between susceptibility and the extent to which several individual autistic traits are exhibited as a continuum in a population of college students. A significant relationship was observed between the systemizing trait and susceptibility to a subset of the tested illusions (the rod-and-frame, Roelofs, Ponzo and Poggendorff illusions). These results provide support for the idea that autism involves an imbalance between the processing of local and global cues, more heavily weighted toward local features than in the typically developed individual.
\end{abstract}

\section{Keywords}

Autism; Perception; Illusions; Systemizing

\begin{abstract}
A diagnosis of autism is based on clinical observations of impairments in social interactions, impairments in communication, and a tendency toward restricted, repetitive and stereotyped interests and behaviors (DSM-IV, American Psychiatric Association, APA 1994). Though this checklist does not include differences in perceptual processing per se, these differences do exist, with demonstrated deficits in, for example, the ability to discriminate biological motion (Blake et al. 2003) and the interpretation of impossible figures (Mottron et al. 1999). In contrast, relatively robust "islands" of enhanced ability have been found in individuals with autism performing certain visual tasks, such as the Block Design (Allen et al. 1991; Shah and Frith
\end{abstract}

\footnotetext{
Correspondence to: Paul Dassonville.

Present Address:

E. Walter, Center for Interdisciplinary Brain Sciences Research, Stanford University, Stanford, CA, USA

Present Address:

T. M. Bochsler Department of Psychology, University of Minnesota, Minneapolis, MN, USA

${ }^{1}$ Participants also completed additional tasks to assess other aspects of cognitive processing, including hidden figures, intuitive physics, digit symbol-coding and global-local processing. Whereas the present report is designed to specifically address questions that relate to illusion susceptibility and autism, the results from these additional tasks will be discussed elsewhere (for a preliminary report, see Dassonville et al. 2007).
} 
1993) and Embedded Figures Tasks (EFT; Shah and Frith 1983; Jolliffe and Baron-Cohen 1997).

Several influential theories have attempted to address both the diagnostic behaviors and the perceptual differences associated with autism. One set of these theories, represented most notably by the Weak Central Coherence theory (WCC; Frith 1989), proposes that the primary factor underlying the autism spectrum disorders (ASD) is a core deficit in the ability to integrate contextual information (the underconnectivity theory of Just et al. 2004, suggests a neural mechanism by which this deficit might occur). In turn, this deficit would lead to an inability to respond in a typical manner to higher-level social or linguistic stimuli that are dependent on an understanding of these contextual cues. At the same time, this deficit could explain the enhanced ability in certain visuospatial tasks (for example, in the EFT, where an inability to focus on the gestalt of the stimulus would allow for a tighter focus on the local elements that make up the embedded figure). A more recent revision of WCC theory suggests that ASD is more akin to a preferred processing bias rather than a static deficit in processing abilitiesthat is, individuals with autism are less likely to integrate contextual elements, though they may be able to do so under certain circumstances (Happé and Frith 2006). Whereas the WCC account of autism proposes an imbalance in the use of local and global cues caused by a deficit in (or bias against) the use of global cues, the Enhanced Perceptual Functioning (EPF) account proposes that the autistic brain, compared to the typically developed brain, has a superior ability for low-level perceptual processing (Mottron and Burack 2001; Mottron et al. 2006). In turn, this enhanced perceptual ability (as well as those suggested by related theories, such as that of Plaisted 2001) would lead to an overdependence on local cues in the sensory stimulus, perhaps at the expense of the ability to integrate objects and events over time and space.

Although the focus of the WCC and EPF accounts are somewhat different, both predict that individuals with autism should be relatively less susceptible to many visuospatial illusions, as they should be less able or less inclined to integrate the (misleading) contextual elements that give rise to the illusions. However, studies investigating visual illusion susceptibility in autism have produced mixed results. Initial reports of relative immunity to illusions (Happé 1996; see also Bölte et al. 2007) were soon followed by findings that individuals with autism and those without are equally susceptible to illusions (Ropar and Mitchell 1999, 2001; Hoy et al. 2004). However, a real difference in susceptibility might have been obscured by the circumstances under which the studies were performed, with clinical populations being compared to various types of control populations. First, there is the difficulty in dealing with differences in mental ability between the groups. Typically, this issue is mitigated by selecting a control group matched to the mental age of the ASD group (as measured by standardized tests such as the British Picture Vocabulary Scale, Dunn et al. 1982; or the Kaufman Brief Intelligence Test, Kaufman and Kaufman 1990), but by design this leads to differences in chronological age. These differences are problematic in the context of measuring illusion susceptibilities, since it is known that susceptibilities are modulated by age. Although various authors have suggested that susceptibility matures to adult-like levels sometime between the ages of 6 years (e.g., Weintraub 1979; Zanuttini 1996) and 15 years (e.g., Brosvic et al. 2002; Bondarko and Semenov 2004), other authors have suggested that susceptibility changes throughout the lifetime (Coren and Girgus 1978; Coren and Porac 1978; Porac and Coren 1981; Leibowitz and Judish 1967). Of course, one could instead compare an ASD group to a control group matched for chronological age, but this would in turn introduce a confound if susceptibility is instead correlated to mental age.

Another potential confound brought about by a comparison of a clinical population with a control group lies in the heterogeneity of the clinical group itself. This would be especially true if the clinical group contained individuals across the autistic spectrum. However, it is also true even if the participants were uniform in their diagnoses, given the great heterogeneity in 
cognitive abilities and severity of impairments seen among individuals with any one of the spectrum disorders (Happé et al. 2006; Baron-Cohen et al. 2003; Belmonte et al. 2004; Ring et al. 2008). This effect is only further magnified once individual differences in co-morbid disorders are considered (Gillberg and Billstedt 2000). Given the relatively small numbers of participants tested in studies of the cognitive effects of ASD, this within-group heterogeneity could potentially obscure a true difference between groups unless it is quantified and partialled out within the statistical analyses of the results.

Although studies of group differences have done much to further our understanding of autism and will undoubtedly continue to do so, other methods possess strengths that can complement those of the group differences approach. An alternative way to study the impact of autistic traits on visuospatial processing, without introducing the confounds of age differences, co-morbidity and variable symptoms, is to compare measures of autistic tendencies to individual differences in visuospatial processing ability within a typically developing population. Three self-report measures, the Autism Quotient (AQ), Systemizing Quotient (SQ), and Empathizing Quotient (EQ) have been developed by Baron-Cohen and colleagues to measure traits associated with autism within the general population. The AQ (Baron-Cohen et al. 2001) has five subscales (social skill, attention switching, attention to detail, communication, imagination) each designed to quantify a set of behavioral traits associated with autism. Systemizing refers to the ability and predilection for analyzing, understanding and building complex systems, tendencies strongly exhibited by individuals with ASD. An individual with a high SQ (Baron-Cohen et al. 2003) would be better able to integrate information about the constituent parts of a system in order to understand how it works and to predict outcomes. In contrast, empathizing refers to the ability to infer what other individuals are thinking or feeling. An individual with a high EQ (Baron-Cohen and Wheelwright 2004) would feel comfortable in social situations and be able to respond appropriately to the emotions noticed in others (a trait that is typically impaired in ASD).

All three of these trait measures (the AQ, SQ and EQ) have been demonstrated to vary continuously in the general population, with individuals on the autistic spectrum (and often their family members) occupying the extremes of the continua (Baron-Cohen et al. 2001, 2003; Baron-Cohen and Wheelwright 2004). Though relatively new, these measures do possess good test-retest reliability (Baron-Cohen et al. 2001, 2006; Baron-Cohen and Wheelwright 2004; Lawrence et al. 2004), cross-cultural validity (Wakabayashi et al. 2007; Wakabayashi et al. 2006), and diagnostic validity (Baron-Cohen et al. 2005; Woodbury-Smith et al. 2005). The use of these continuous measures as a means of quantifying particular autistic traits, rather than assigning each participant to a discrete group ("autistic" or "typical"), should provide a means to uncover correlations between performance on visuospatial tasks and trait strength. In addition, it would allow for the assessment of the effects of a specific autistic trait rather than treating all traits associated with autism as a package. An additional advantage to this continuous-trait methodology stems from the ability to measure hundreds of easily obtained, typically developing participants, rather than studying a smaller number of participants with an ASD diagnosis. The present study uses this methodology to test the hypothesis that illusion susceptibility is modulated by the extent to which individuals exhibit the traits of autism. Since a previous report has indicated that autism may affect susceptibility to some illusions but not others (Happé 1996), a wide variety of illusions are tested. However, to increase the statistical power of our comparisons, we will also use the method of factor analysis to combine the results across the illusions, in order to isolate specific factors that reflect different mechanisms that underlie broad patterns of illusion susceptibility. 


\section{Methods}

\section{Participants}

Participants were University of Oregon undergraduates who took part in this experiment in exchange for credit in an introductory psychology course, with consent established as per the University of Oregon Institutional Review Board. In all, 321 individuals with normal or corrected-to-normal vision participated (190 females), with an average age of $19.9(\mathrm{SD}=2.7)$ years. All participants performed a subset of tasks (AQ, EQ, SQ, rod-and-frame and Roelofs), whereas a subset of these individuals $(N=146)$ completed a longer battery that also included other visual illusions (induced motion, Zöllner, Ponzo, Poggendorff, Ebbinghaus, and MüllerLyer). ${ }^{1}$ Approximately $1-2 \mathrm{~h}$ was necessary for completion of the full battery of tasks.

However, due to occasional equipment malfunctions and individual differences in the amount of time taken to perform the tasks, some participants were not able to complete the entire battery and thus did not contribute a full set of results. In the analyses, data were included in a pairwise manner, with no attempt to replace missing data with averages or other values.

\section{Procedures}

Illusion Susceptibility-For each illusion, stimuli were presented at or slightly above eyelevel, with the participant sitting at a desk in a darkened room. Stimuli were back-projected onto a translucent screen $(128 \mathrm{~cm} \times 96 \mathrm{~cm})$ by a Barco Cine 7 projector with a screen refresh rate of $60 \mathrm{~Hz}$. Participants sat at a comfortable viewing distance (approximately $122 \mathrm{~cm}$ ) from the screen, with the head free and no eye-movement restrictions. Unless otherwise noted, stimuli were red, presented on a black background in otherwise complete darkness. Susceptibility to each illusion was assessed by the method of adjustment, with the participants required to press keys on a standard keyboard to adjust the characteristics (orientation, position, length or size) of a comparison stimulus (see Fig. 1) to match a world-based reference (gravitational vertical in the rod-and-frame and induced motion illusions), an egocentricallydefined reference (the midsagittal plane in the induced Roelofs effect), or a second stimulus presented in an illusion-causing context (Ponzo, Poggendorff, Zöllner, Müller-Lyer, Ebbinghaus illusions). Whereas the home keys "f" and " $\mathrm{j}$ " of the keyboard adjusted the characteristics of the comparison stimulus in fine increments $\left(1^{\circ}\right.$ counterclockwise or clockwise, respectively, when adjusting orientation; 1 pixel left or right, respectively, when adjusting position; or 1 pixel larger or smaller, respectively, when adjusting size or length), keys "d" and "k" adjusted in coarse increments ( $5^{\circ}$ or 8 pixels). Thus, participants used the coarse control keys to quickly move the target toward its goal, then the fine control keys to precisely adjust the target's final position. In each task, participants were given a brief practice session performed without the illusion-inducing context present before the experimental trials commenced. Each of the tasks took approximately 5-10 min to complete.

Susceptibility was measured in each of eight illusions (Fig. 1).

Rod-and-Frame Illusion-A tilted frame causes an enclosed line (the "rod") to appear tilted in the opposite direction (Witkin and Asch 1948). In the present study, participants adjusted the orientation of the rod so that it appeared to be vertical (32 trials).

Induced Roelofs Effect-When a target is presented within the context of a large frame whose center is shifted left or right of the observer's midline, the perceived location of the target is biased in the opposite direction (Bridgeman et al. 1997; Dassonville and Bala 2004;

Present Address:

E. Walter, Center for Interdisciplinary Brain Sciences Research, Stanford University, Stanford, CA, USA 
Dassonville et al. 2004). Participants moved the target so that it appeared to lie "straight ahead," directly in front of the nose (32 trials).

Induced Motion-When a target is presented on a moving background, the motion of the background can induce an illusory motion of the target in the opposite direction (Duncker 1938). If the target itself is moving, its real (or apparent) motion will be combined with an illusory component in the direction opposite the motion of the background. Participants adjusted the orientation of the targets so that they appeared to be moving in a purely vertical direction (16 trials).

Zöllner Illusion-When a target line is cross-hatched by a set of obliquely-oriented inducing lines, the target line appears to be tilted in the opposite direction (Zöllner 1860; Kitaoka and Ishihara 2000). Participants adjusted the orientation of a comparison line so that it matched that of the target line (24 trials).

Ponzo Illusion-When a horizontal line is presented in the context of two converging lines that appear to be parallel lines that recede in the distance, the target line appears to be longer when it is presented in the far space of the receding lines or shorter when presented in the near space (Ponzo 1912). Participants adjusted the length of a comparison line to match the length of the target line that was presented within the context of the illusion (24 trials).

Ebbinghaus (Titchener) Illusion-When a circle is centered within a ring of larger (or smaller) circles, the contrast causes the center circle to appear smaller (or larger) than its actual size (Wundt 1898; Titchener 1901). Participants adjusted the diameter of a comparison circle to match that of the target circle (24 trials).

Müller-Lyer Illusion-When a target line has arrow-shaped inducers attached to its ends, inward-pointing inducers cause an increase in the line's perceived length, whereas outwardpointing inducers cause a decrease (Müller-Lyer 1889). Participants adjusted the length of a comparison line so that it appeared to match that of the target line (24 trials).

Poggendorff Illusion-When an objectively straight line is obscured by another object (usually a rectangular box), the line-ends appear to be offset from each other (Burmester 1896). Participants adjusted the position of a line segment that protruded from the top of the box, so that it appeared to lie collinear with the line segment that protruded from the bottom of the box ( 24 trials).

Errors in stimulus adjustment for each illusion type were measured in degrees of visual angle (induced Roelofs, Ponzo, Ebbinghaus, Müller-Lyer, and Poggendorff illusions) or degrees of rotation (rod-and-frame, induced motion, and Zöllner illusions). General measures of illusion susceptibility were then obtained by submitting the z-normalized results from the individual illusion tests to a principle components analysis (varimax rotation), retaining those factors with eigenvalues greater than 1.0 (SPSS 11.0, SPSS, Inc.).

The Autism-spectrum, Empathizing and Systemizing Quotients-In addition to the tests of illusion susceptibility, participants completed the questionnaires designed by BaronCohen and colleagues to measure AQ, EQ and SQ. In each, participants were asked to read various statements (e.g., "When I am reading a story, I can easily imagine what the characters might look like.") and then rate the extent to which the statement described himself or herself ("Definitely agree," "Slightly agree," "Slightly disagree," or "Definitely disagree"). The AQ (Baron-Cohen et al. 2001) contains 50 questions, with each question that is answered in the direction most often associated with autism scoring one point, regardless of which modifier ("Slightly" or "Definitely") is indicated. Questions answered in the opposite direction were 
scored zero points. The EQ (Baron-Cohen and Wheelwright 2004) and SQ (Baron-Cohen et al. 2003) each contains 40 items (and an additional 20 filler items), with each question answered in the way that indicates the tendency to empathize (or systemize) scoring one point (when accompanied by the modifier "Slightly") or two points (when accompanied by the modifier "Definitely").

\section{Results $A Q, E Q$ and $S Q$}

Across all participants, the mean scores on the AQ, EQ and SQ were $15.3(\mathrm{SD}=5.6$; range $=$ $1-32), 44.7(\mathrm{SD}=10.8$; range $=19-78)$ and $28.0(\mathrm{SD}=12.3$; range $=5-66)$, respectively .

Although a one-sample Kolmogorov-Smirnov test demonstrated that the EQ distribution did not differ significantly from normality $(\mathrm{K}-\mathrm{S} \mathrm{Z}=1.035)$, AQ was found to be significantly nonnormal $(\mathrm{K}-\mathrm{S} \mathrm{Z}=1.486, p=0.024)$ and $\mathrm{SQ}$ trended toward non-normality $(\mathrm{K}-\mathrm{S} \mathrm{Z}=1.257, p$ $=0.085$ ); for this reason, subsequent analyses of these measures used nonparametric statistical tests. Two-sample $\mathrm{K}-\mathrm{S}$ tests indicated the expected gender differences in SQ (mean male SQ $=32.7$, female $=24.8 ; \mathrm{K}-\mathrm{S} \mathrm{Z}=2.452, p<0.001)$ and $\mathrm{EQ}($ mean male $\mathrm{EQ}=41.8$, female $=$ 46.6 ; $\mathrm{K}-\mathrm{S} \mathrm{Z}=1.536, p=0.018$ ); although the gender difference in the AQ scores trended in the expected direction, it did not reach significance (mean male $\mathrm{AQ}=15.6$, female $=15.0 ; \mathrm{K}-$ $\mathrm{SZ}=1.097, p=0.18$ ). As has been previously demonstrated (Baron-Cohen et al. 2003), AQ had a significant negative correlation with EQ (Spearman's rho, $r_{\mathrm{s}}=-0.320, p<0.001$, with the negative correlation explainable by an inverse method of coding the answers in the AQ and EQ questionnaires) and a weaker positive correlation with SQ $\left(r_{\mathrm{s}}=0.148, p=0.009\right)$. EQ and $\mathrm{SQ}$ were found to be uncorrelated $\left(r_{\mathrm{s}}=0.089\right.$, n.s.; see also Lawson et al. 2004).

\section{Illusion Susceptibility}

Each of the illusion paradigms successfully generated the expected bias in perception, with significant effects noted in each (Zöllner: $t(159)=21.564, p<0.001$, two-tailed; Roelofs: $t$ $(308)=13.149, p<0.001$; rod-and-frame: $t(308)=14.696, p<0.001$; Ponzo: $t(126)=14.254$, $p<0.001$; Poggendorff: $t(159)=26.431, p<0.001$; Ebbinghaus: $t(159)=24.423, p<0.001$; Müller-Lyer: $t(159)=46.924, p<0.001$; induced motion: $t(163)=31.312, p<0.001)$. We also obtained general measures of illusion susceptibility by delineating groups of illusions whose susceptibilities co-varied across the participants. This was accomplished by a principle components analysis that took as its input the susceptibility measures from each of the illusions. The output of this analysis uncovered two factors that accounted for a combined $40.7 \%$ of the total variance from the results of the eight illusion tasks (Table 1). The first of these factors (illusion susceptibility factor \#1) was driven mainly by susceptibilities to the Zöllner, Roelofs, rod-and-frame, Ponzo, Poggendorff and Ebbinghaus illusions, accounting for 25.0\% of the total variance. In contrast, the second factor (illusion susceptibility factor \#2) was driven mainly by susceptibilities to the induced motion, Ebbinghaus and Müller-Lyer illusions, accounting for an additional $15.8 \%$ of the total variance.

Given that the intent of performing the principle components analysis was to isolate factors that might underlie susceptibilities across subsets of the tested illusions, subsequent analyses were performed on factors that were modified from those described above. In particular, since the Ebbinghaus illusion proved to be non-diagnostic in the sense that it contributed to both susceptibility factors, it was eliminated from further consideration. The individual factors were also modified by eliminating the individual illusions that failed to provide loading weights that surpassed the threshold of 0.4 in the different factors. The resulting susceptibility factor $\# 1_{\text {mod }}$ accounted for $35.7 \%$ of the total variance from the Zöllner, Roelofs, rod-and-frame, Ponzo and Poggendorff illusions, and susceptibility factor $\# 2_{\bmod }$ accounted for $55.94 \%$ of the total variance from the Müller-Lyer and induced motion illusions. 


\section{The Relationship Between Illusion Susceptibility and Autistic Traits}

In a comparison of AQ, EQ and SQ scores to illusion susceptibility, a significant negative correlation was seen between susceptibility factor \# $1_{\text {mod }}$ and SQ (even when using a Bonferroni-corrected significance level of $p<0.008$ ); that is, a greater SQ corresponded to a decrease in the combined susceptibilities to the Zöllner, rod-and-frame, Roelofs, Ponzo and Poggendorff illusions (Table 2). This relationship had a moderate effect size, with a Cohen's $d$ of 0.72 (Cohen 1992). In contrast, this susceptibility factor was not correlated with EQ or $\mathrm{AQ}$, nor was it correlated with any of the individual subcomponents of AQ (social skill, attention switching, attention to detail, communication or imagination; for each, $r_{\mathrm{s}}<-0.104$ ). An examination of susceptibility factor $\# 2_{\text {mod }}$ found no significant relationships between AQ, EQ or SQ (Table 2), nor any of the individual subcomponents of AQ (for each, $r_{\mathrm{s}}<-0.084$ ).

Because SQ is known to differ significantly between men and women (Baron-Cohen et al. 2003), as is the susceptibility to some illusions (e.g., Girgus and Coren 1987; Philips et al. 2004; Voyer et al. 1995; but see also Porac et al. 1979), it is important to determine whether the correlation between SQ and illusion susceptibility is merely driven by gender differences. This was accomplished with a linear regression that separately assessed the contributions of gender and SQ on susceptibility factor \# $1_{\text {mod }}$, using ranked SQ and susceptibility scores for a nonparametric test. Even after partialling out the effects of gender in this way, SQ was found to account for a significant additional $8.9 \%$ of the total variance explained $(p=0.001)$.

With a participant population drawn from college students, it is certainly possible that a portion of our participants were on the autism spectrum (with or without actual clinical diagnoses as such). Given this, it may be that the correlation between SQ and illusion susceptibility reported above reflects not a true continuum, but instead the side-effect of two participant populations (that is, on and off the autism spectrum) that differ qualitatively in both SQ and illusion susceptibility. Baron-Cohen et al. (2001) have suggested that an AQ score of 32 serves as an effective threshold for delineating those on and off the spectrum in the general population. However, only one participant in our sample had an AQ of 32 or more, and eliminating this participant from consideration had no effect on the significance of the relationship between SQ and susceptibility factor $\# 1_{\text {mod }}(p=0.0001)$. Furthermore, the elimination of the 17 participants that surpassed a more liberal threshold of $A Q=26$ (which Woodbury-Smith et al. 2005, demonstrated to be an effective threshold for screening for Asperger syndrome in a group of adults referred for clinic diagnosis of the disorder) also failed to appreciably alter the significance of this relationship $(p=0.0002)$.

Although susceptibility factor \# $1_{\text {mod }}$ was found to correlate with SQ, this relationship may have been driven by only one or a few of the illusions that contributed to the factor. To test this, the magnitude of the susceptibilities to the individual illusions were directly compared to SQ. Of the five illusions that contributed to susceptibility factor $\# 1_{\text {mod }}$, the Roelofs $\left(r_{\mathrm{S}}=-\right.$ $0.181, p=0.001$; Cohen's $d=0.37)$, rod-and-frame $\left(r_{\mathrm{s}}=-0.155, p=0.006 ; d=0.31\right)$, Ponzo $\left(r_{\mathrm{S}}=-0.270, p=0.002 ; d=0.56\right)$ and Poggendorff illusions $\left(r_{\mathrm{s}}=-0.170, p=0.032, d=0.35\right)$ were significantly correlated with SQ. In contrast, susceptibility to the Zöllner illusion was not significantly correlated with SQ $\left(r_{\mathrm{S}}=-0.091\right.$, n.s. $)$, nor was susceptibility to the Ebbinghaus illusion $\left(r_{\mathrm{s}}=-0.023\right.$, n.s. $)$, which had contributed to both of the original susceptibility factors $\# 1$ and \#2.

\section{Discussion}

Previous evidence has indicated that the autistic brain uses a different balance of global and local cues for visual processing than that used by the non-autistic brain (e.g., Happé and Frith 2006; Mottron et al. 2006). This has, in turn led to speculation that individuals with autism would be less susceptible to visual illusions than are typically developing individuals. 
However, published evidence for this immunity to illusions is inconsistent, at best (Happé 1996; Bölte et al. 2007; but see also Ropar and Mitchell 1999, 2001; and Hoy et al. 2004). In the present study, we sought to determine whether a link between autism and illusion susceptibility could be more convincingly demonstrated by taking into account the extent to which individuals exhibit various autistic traits. The findings demonstrate a significant correlation between the autistic trait of systemizing and susceptibility to a subset of the tested illusions. In particular, systemizing was negatively correlated with a general illusion susceptibility factor that combined the susceptibilities to the rod-and-frame, Roelofs, Ponzo, Poggendorff and Zöllner illusions. When tested individually, the susceptibilities to four of the five illusions (with the exception of the Zöllner illusion) were also correlated with SQ scores, demonstrating that this relationship reflected a general phenomenon rather than one driven by the artifactual correlation of only a single illusion. Susceptibility to another set of illusions (induced motion and Müller-Lyer, the major components of susceptibility factor $\# 2_{\text {mod }}$ ) was not found to correlate with any of the tested autistic traits.

Baron-Cohen coined the term 'systemizing' to refer to the drive or tendency to analyze the variables of a system, so that one can predict and control the system's behavior (Baron-Cohen et al. 2003). Given that this tendency would require an attentional focus on the details of the system's parameters, it is perhaps not surprising that systemizing would be correlated with illusion susceptibility, since a greater focus on the relevant details of an illusory stimulus (for example, the rod of the rod-and-frame illusion), and an accompanying decrease in the processing of the illusion-causing context (i.e., the frame), would lead to a decreased susceptibility. In this way, systemizing seems very much related to the ideas of the WCC (Frith 1989; Happé and Frith 2006) and EPF (Mottron and Burack 2001; Mottron et al. 2006) theories of autism. Indeed, Baron-Cohen has theorized direct links between systemizing and WCC, noting that the "... attention to detail described by WCC may be one of the earliest manifestations of a strong drive toward systemizing, or vice versa, interest in systemizing may arise as a consequence of attention to detail," (Baron-Cohen and Belmonte 2005, p. 112). Happé and Frith (2006, p. 19) propose a similar link, noting that “....some systems (e.g., bus route numbering) may be fathomable through 'local' coherence, provided that simple if-then rules operate without context-dependent effects. Mastery of such systems would not be counter to the coherence account." Furthermore, Billington et al. (2008) have recently demonstrated that SQ scores are correlated with a measure of local/global precedence using Navon figures, a finding that further suggests a relationship between systemizing and the underlying neural processes at the heart of the WCC and EPF theories.

Given the finding of a relationship between illusion susceptibility and SQ, it is somewhat surprising that there was no significant correlation between susceptibility and AQ or its subscales. In particular, the AQ subscale of 'attention to detail' would seem to measure at least one component of the systemizing tendency; indeed, 'attention to detail' was the AQ subscale that was most strongly correlated to SQ within our participants $\left(r_{\mathrm{s}}=0.322, p<0.001\right.$; the only other subscale significantly correlated with SQ was 'imagination', $r_{\mathrm{s}}=0.119, p<0.05$ ). However, the relationship between 'attention to detail' and SQ did not also translate into a correlation between 'attention to detail' and susceptibility factor $\# 1_{\bmod }\left(r_{\mathrm{s}}=-0.055, p=0.547\right)$. It is very likely that a contributing factor for this null finding is the fact that 'attention to detail' is assessed with only 10 of the 50 questions that comprise the AQ questionnaire, whereas systemizing is assessed with 40 questions within the SQ questionnaire. Thus, the 'attention to detail' subscale is undoubtedly less reliable than SQ as a measure of the systemizing trait.

The finding that illusion susceptibility is correlated with the autistic trait of systemizing echoes the results of Happé (1996) and Bölte et al. (2007), who found that susceptibility in children with autism was somewhat less than that seen in a typically developing population. Given our findings, one might wonder why Ropar and Mitchell (1999, 2001) and Hoy et al. (2004) failed 
to find a difference in susceptibility in a comparison of similar groups. Our finding that the susceptibility to only a subset of illusions was associated with systemizing might lead to speculation that these other studies simply examined illusions that did not show this relationship. However, this was not the case, since the studies of Ropar and Mitchell (1999, 2001) and Hoy et al. (2004) did include two of the four illusions that were seen here to be correlated with SQ (including the Ponzo illusion, which had the largest effect size). In an earlier report, Brosnan et al. (2004) speculated that the discrepancies seen in the findings of Happé (1996) and Ropar and Mitchell $(1999,2001)$ might have been due to differences in the participants' method of responding, with Happé requiring a verbal, categorical judgment of the stimuli (e.g., "Are the two lines the same length or different lengths?") and Ropar and Mitchell requiring participants to null the effects of the illusion by the method of adjustment. However, the current results, in which a relationship between SQ and illusion susceptibility was found using the method of adjustment, would seem to rule out differences in the method of responding as a possible explanation.

Other possible reasons for this discrepancy do exist, with the most striking difference between the studies of Ropar and Mitchell $(1999,2001)$ and ours being the logic by which the paradigms were designed. In their first study of the issue, Ropar and Mitchell (1999, experiment 1) carried out a straightforward examination of the illusion susceptibilities of three clinical populations (with diagnoses of autism, Asperger syndrome or moderate learning difficulties, and mean chronological/mental ages of 13/7, 14/14 and 10/6 years), plus three groups of typically developing controls (with mean chronological ages of 8,11 and 17 years). Although this type of comparison is standard in the literature on developmental disorders, it is nonetheless subject to confounds brought about by the different ages of the participant groups, with illusion susceptibility known to change during development. In addition, differences in the extent to which various autistic traits and co-morbid disorders are exhibited by individuals in a clinical population could potentially obscure any real differences in the dependent variable being tested in a given study. In contrast, the present study tested a population of undergraduate college students by comparing individual differences in illusion susceptibility to a quantification of the extent to which these individuals possessed different autistic traits. As a result, this paradigm minimizes the possible confounds brought about by group differences in chronological age, mental age and co-morbidity, and has the added benefit of allowing the testing of a large number of easily-obtained participants.

A more mundane difference between the present study and those of Hoy et al. (2004) and Ropar and Mitchell $(1999,2001)$ lies in the statistical power of the analyses performed. The participants of Ropar and Mitchell were tested with far fewer trials (40, 64 and 24 trials in experiments 1 and 2 of Ropar and Mitchell 1999, and 2001, respectively) than the participants of the present study (200 trials for approximately half of the participants, and 80 trials for the remainder). The three experiments of Ropar and Mitchell also differed with the present study in the total number of participants, with 109 participants (13-23 participants in each of 5 experimental groups; Ropar and Mitchell 1999, experiment 1), 99 participants (17-35 participants in each of 4 groups; Ropar and Mitchell 1999, experiment 2) and 87 participants (11-20 participants in each of 5 groups; Ropar and Mitchell 2001) tested. Hoy et al. (2004) tested only 34 participants (17 participants in 2 groups). In contrast, the present study examined the relationship between illusion susceptibilities and autistic traits as continua in a moreuniform sample of 127 college students (or 321 participants for the more direct comparisons of SQ and susceptibilities to the Roelofs and rod-and-frame illusions).

It is generally assumed in the visual perception literature that visuospatial illusions are not all driven by the same underlying mechanism (Coren et al. 1976; Coren and Porac 1987;

Prinzmetal and Beck 2001), and indeed, some may be driven by mechanisms that impact wide ranging levels of visual processing (Dyde and Milner 2002). Given this, it could also be 
assumed that the susceptibilities to different illusions would be more or less correlated to the various autistic traits. Indeed, the original work of Happé (1996) found that although susceptibilities to a subset of illusions (Ponzo, Poggendorff, Ebbinghaus, Hering and Kanisza) were decreased in an autistic population, Müller-Lyer susceptibility was not. This pattern of findings fit well with those presented here, where only the Ponzo, Poggendorff, rod-and-frame, Roelofs, and Zöllner illusions were negatively correlated with systemizing (albeit with the Zöllner illusion only as part of susceptibility factor $\# 1_{\text {mod }}$ ). The recent work of Prinzmetal and colleagues (Prinzmetal and Beck 2001; Shimamura and Prinzmetal 1999) provides a strong clue as to the reason why susceptibility to these illusions might have co-varied in a way that caused them to group together within a single susceptibility factor. Prinzmetal and Beck (2001) found that the effects of the Zöllner, Poggendorff, Ponzo and tilt-induction illusions (the latter related to the rod-and-frame effect) were magnified when observers made their judgments while the head and body were tilted $30^{\circ}$ from vertical. In contrast, the Müller-Lyer and a size constancy illusion did not show this effect. These authors suggest that the affected illusions were all driven by context-related distortions of the observer's perception of vertical and horizontal directions. In the present study, we found that the Roelofs effect co-varied with this group of tilt-induction illusions, suggesting that it also shares a common underlying mechanism. Previous demonstrations that the Roelofs effect involves a distortion of perceived straight-ahead (Dassonville and Bala 2004; Dassonville et al. 2004) suggests the need to broaden Prinzmetal and Beck's "tilt-constancy theory of visual illusions" (Prinzmetal and Beck 2001) to include other illusions that are manifest by context-related distortions of the observer's spatial reference frame but are not affected by tilt constancy, per se. Further work is needed to understand why susceptibility to these illusions, but not others, is related to the systemizing trait of autism.

One obvious limitation of the present study is that it does not include the direct examination of illusion susceptibility in an autistic population, and this restricts our ability to definitively state that individuals with autism are less susceptible than the typically developing population. However, inasmuch as it is believed that systemizing is an autistic trait that forms a continuum across the general population (with autistic individuals generally falling at the upper end of this continuum, Baron-Cohen et al. 2003), the current study clearly demonstrates a link between the systemizing trait and susceptibility to at least a subset of visuospatial illusions. These findings generally support the idea that autism entails, at least in part, an atypical balance between the use of local and global cues in visuospatial perception. However, it remains to be determined whether this imbalance is manifest as an increased focus on local elements (as suggested by the theory of EPF, Mottron et al. 2006), a decreased use of global cues (as suggested by the theory of WCC, Happé and Frith 2006), or some combination of the two. Previous studies specifically designed to quantify the separate local and global influences in autistic perception typically used paradigms that would have been susceptible to the various confounds of comparing participants within clinical groups that are all too heterogeneous, which might explain why the results of those studies have been so inconsistent (see Table 1 of Hoy et al. 2004). It is probable that this research question and others like it would greatly benefit from the use of a continuous-trait methodology similar to the one used in the present study, with sensory and cognitive processing abilities and tendencies directly compared to the magnitude of specific autistic traits within individuals. To fully understand autism and the related disorders, it will undoubtedly be necessary to combine the strengths of various approaches.

\section{Acknowledgments}

This work was derived from a portion of the doctoral dissertation of Elizabeth Walter, and was partially supported by an NIH Systems Physiology Training Grant (5-T32-GM07257). It was presented at the 2007 Annual Meeting of the Vision Science Society. We thank Ulrich Mayr for his advice on the statistical analyses. 


\section{References}

Allen M, Lincoln A, Kaufman A. Sequential and simultaneous processing abilities of high-functioning autistic children and language impaired children. Journal of Autism and Developmental Disorders 1991;21:483-502. [PubMed: 1778962]doi: 10.1007/BF02206872.

American Psychiatric Association. Diagnostic and statistical manual of mental disorders. Vol. 4th ed. Washington, DC: Author; 1994.

Baron-Cohen S, Belmonte MK. Autism: A window onto the development of the social and the analytical brain. Annual Review of Neuroscience 2005;28:109-126.doi: 10.1146/annurev.neuro.27.070203.144137.

Baron-Cohen S, Hoekstra RA, Knickmeyer R, Wheelwright S. The autism-spectrum quotient (AQ) Adolescent version. Journal of Autism and Developmental Disorders 2006;36:343-350. [PubMed: 16552625]doi: 10.1007/s10803-006-0073-6.

Baron-Cohen S, Richler J, Bisarya D, Gurunathan N, Wheelwright S. The systemizing quotient: an investigation of adults with Asperger syndrome or high-functioning autism, and normal sex differences. Proceedings of the Royal Society of London Series B Biological Sciences 2003;358:361374.doi: 10.1098/rstb.2002.1206.

Baron-Cohen S, Wheelwright S. The empathy quotient: An investigation of adults with Asperger syndrome or high functioning autism, and normal sex differences. Journal of Autism and Developmental Disorders 2004;34:163-175. [PubMed: 15162935]doi: 10.1023/B:JADD.0000022607.19833.00.

Baron-Cohen S, Wheelwright S, Robinson J, Woodbury-Smith M. The adult asperger assessment (AAA): A diagnostic method. Journal of Autism and Developmental Disorders 2005;35:807-819. [PubMed: 16331530]doi: 10.1007/s10803-005-0026-5.

Baron-Cohen S, Wheelwright S, Skinner R, Martin J, Clubley E. The autism-spectrum quotient (AQ): Evidence from Asperger syndrome/high-functioning autism, males and females, scientists and mathematicians. Journal of Autism and Developmental Disorders 2001;31:5-17. [PubMed: 11439754] doi: 10.1023/A:1005653411471.

Belmonte MK, Cook EH Jr, Anderson GM, Rubenstein JLR, Greenough WT, Beckel-Mitchener A, et al. Autismasa disorder of neural information processing: Directions for research and targets for therapy. Molecular Psychiatry 2004;9:646-663. [PubMed: 15037868]

Billington J, Baron-Cohen S, Bor D. Systemizing influences attentional processes during the Navon task: An fMRI study. Neuropsychologia 2008;46:511-520. [PubMed: 17963797]doi: 10.1016/j.neuropsychologia.2007.09.003.

Blake R, Turner L, Smoski M, Pozdol S, Stone W. Visual recognition of biological motion is impaired in children with autism. Psychological Science 2003;14:151-157. [PubMed: 12661677]doi: 10.1111/1467-9280.01434.

Bölte S, Holtmann M, Poustka F, Scheurich A, Schmidt L. Gestalt perception and local-global processing in high-functioning autism. Journal of Autism and Developmental Disorders 2007;37:1493-1504. [PubMed: 17029017]doi: 10.1007/s10803-006-0231-x.

Bondarko VM, Semenov LA. Size estimates in Ebbinghaus illusions in adults and children of different age. Human Physiology 2004;30:24-30.doi: 10.1023/B:HUMP.0000013760.85499.17.

Bridgeman B, Peery S, Anand S. Interaction of cognitive and sensorimotor maps of visual space. Perception and Psychophysics 1997;59:456-469. [PubMed: 9136275]

Brosnan MJ, Scott FJ, Fox S, Pye J. Gestalt processing in autism: Failure to process perceptual relationships and the implications for contextual understanding. Journal of Child Psychology and Psychiatry, and Allied Disciplines 2004;45:459-469.doi: 10.1111/j.1469-7610.2004.00237.x.

Brosvic DM, Dihoff RE, Fama J. Age-related susceptibility to the Müller-Lyer and the horizontal-vertical illusions. Perceptual and Motor Skills 2002;94:229-234. [PubMed: 11883567]doi: 10.2466/PMS.94.1.229-234.

Burmester E. Beitrage zur experimentellen Bestimmung geometrisch-optischer Täuschungen. Zeitschrift für Psychologie und Physiologie der Sinnesorgane 1896;12:355-394.

Cohen J. A power primer. Psychological Bulletin 1992;112:155-159.doi: 10.1037/0033-2909.112.1.155. 
Coren, S.; Girgus, J. Seeing is deceiving: The psychology of visual illusions. Hillsdale, NJ: Lawrence Erlbaum Associates; 1978.

Coren S, Girgus J, Erlichman H, Hakstian AR. An empirical taxonomy of visual illusions. Perception and Psychophysics 1976;20:129-137.

Coren S, Porac C. A new analysis of life-span age trends in visual illusion. Developmental Psychology 1978;14:193-194.doi: 10.1037/0012-1649.14.2.193.

Coren S, Porac C. Individual differences in visual-geometric illusions: Predictions from measures of spatial cognitive abilities. Perception and Psychophysics 1987;41:211-219. [PubMed: 3575080]

Dassonville P, Bala JK. Action, perception and the Roelofs effect: A mere illusion of dissociation. PLoS Biology 2004;2:1936-1945.doi: 10.1371/journal.pbio.0020364.

Dassonville P, Bridgeman B, Bala J, Thiem P, Sampanes A. The induced Roelofs effect: two visual systems or the shift of a single reference frame? Vision Research 2004;44:603-611. [PubMed: 14693187]doi: 10.1016/j.visres.2003.10.017.

Dassonville, P.; Walter, E.; Bochsler, TM. Poster Presented at the 7th Annual Meeting of the Vision Sciences Society. Sarasota, FL: 2007. A specific autistic trait that modulates illusion susceptibility.

Duncker K. Induced motion. In W. D. Ellis (Ed.), A source book of gestalt psychology (pp. 161-172). New York: The Humanities Press. Original work published in expanded form as Duncker, K. (1929) Über induzierte Bewegung [Ein Beitrag zur Theorie optisch wahrgenommener Bewegung]. Psychologische Forshung 1938;12:180-259.

Dunn, LM.; Dunn, LM.; Whetton, C.; Pintillie, D. British picture vocabulary scale. Windsor, UK: NFERNelson; 1982.

Dyde RT, Milner AD. Two illusions of perceived orientation: One fools all of the people some of the time; the other fools all of the people all of the time. Experimental Brain Research 2002;144:518 527.doi: 10.1007/s00221-002-1065-1.

Frith, U. Autism: Explaining the enigma. Oxford: Basil Blackwell; 1989.

Gillberg C, Billstedt E. Autism and Asperger syndrome: Coexistence with other clinical disorders. Acta Psychiatrica Scandinavica 2000;102:321-330. [PubMed: 11098802]doi: 10.1034/j.1600-0447.2000.102005321.x.

Girgus J, Coren S. The interaction between stimulus variations and age trends in the Poggendorff illusion. Perception and Psychophysics 1987;41:60-66. [PubMed: 3822745]

Happé F. Studying weak central coherence at low levels: Children with autism do not succumb to visual illusions. A research note. Journal of Child Psychology and Psychiatry, and Allied Disciplines 1996;37:873-877.doi: 10.1111/j.1469-7610.1996.tb01483.x.

Happé F, Frith U. The weak coherence account: Detail-focused cognitive style in autism spectrum disorders. Journal of Autism and Developmental Disorders 2006;36:5-25. [PubMed: 16450045]doi: 10.1007/s10803-005-0039-0.

Happé F, Ronald A, Plomin R. Time to give up on a single explanation for autism. Nature Neuroscience 2006;9:1218-1220.doi: 10.1038/nn1770.

Hoy JA, Hatton C, Hare D. Weak central coherence: A cross-domain phenomenon specific to autism. Autism 2004;8:267-281. [PubMed: 15358870]doi: 10.1177/1362361304045218.

Jolliffe T, Baron-Cohen S. Are people with autism and Asperger Syndrome faster than normal on the embedded figures test? Journal of Child Psychology and Psychiatry, and Allied Disciplines 1997;38:527-534.doi: 10.1111/j.1469-7610.1997.tb01539.x.

Just MA, Cherkassky VL, Keller TA, Minshew NJ. Cortical activation and synchronization during sentence comprehension in high-functioning autism: Evidence of under-connectivity. Brain 2004;127:1811-1821. [PubMed: 15215213]doi: 10.1093/brain/awh199.

Kaufman, AS.; Kaufman, NL. Kaufman brief intelligence test (KBIT). Circle Pines, MN: American Guidance Service; 1990.

Kitaoka A, Ishihara M. Three elemental illusions determine the Zöllner illusion. Perception and Psychophysics 2000;62:569-575. [PubMed: 10909247]

Lawrence EJ, Shaw P, Baker D, Baron-Cohen S, David AS. Measuring empathy: Reliability and validity of the empathy quotient. Psychological Medicine 2004;34:911-919. [PubMed: 15500311]doi: $10.1017 /$ S0033291703001624. 
Lawson J, Baron-Cohen S, Wheelwright S. Empathising and systemising in adults with and without Asperger syndrome. Journal of Autism and Developmental Disorders 2004;34:301-310. [PubMed: 15264498]doi: 10.1023/B:JADD.0000029552.42724.1b.

Leibowitz HW, Judish JM. The relation between age and the magnitude of the Ponzo illusion. The American Journal of Psychology 1967;80:105-109. [PubMed: 6036344]doi: 10.2307/1420548.

Mottron L, Belleville S, Ménard E. Local bias in autistic subjects as evidenced by graphic tasks: Perceptual hierarchization or working memory deficit? Journal of Child Psychology and Psychiatry, and Allied Disciplines 1999;40:743-755.doi:10.1017/S0021963098003795.

Mottron, L.; Burack, J. The development of autism: Perspectives from theory and research. Mahwah, NJ: Erlbaum; 2001. Enhanced perceptual functioning in the development of autism. In J. A. Burack, T. Charman, N. Yirmiya, \& P. R. Zelazo (Eds.); p. 131-148.

Mottron L, Dawson M, Souliéres I, Hubert B, Burack J. Enhanced perceptual functioning in autism: An update, and eight principles of autistic perception. Journal of Autism and Developmental Disorders 2006;36:27-43. [PubMed: 16453071]doi: 10.1007/s10803-005-0040-7.

Müller-Lyer FC. Optische Urteilstäuschungen. Dubois-Reymonds Archive für Anatomie und Physiologie 1889;Supplement:263-270.Deception of visual judgment.

Philips WA, Chapman KLS, Berry PD. Size perception is less context-sensitive in males. Perception 2004;33:79-86. [PubMed: 15035330]doi: 10.1068/p5110.

Plaisted, KC. The development of autism: Perspectives from theory and research. Mahwah, NJ: Erlbaum; 2001. Reduced generalization in autism: An alternative to weak central coherence. In J. A. Burack, T. Charman, N. Yirmiya \& P. R. Zelazo (Eds.); p. 149-169.

Ponzo M. Rapports de contraste angulaire et l'appréciation de grandeur des astres á l'horizon. Archives Italiennes de Biologie 1912;58:327-329.

Porac C, Coren S. Life-span age trends in the perception of the Mueller-Lyer: Additional evidence for the existence of two illusions. Canadian Journal of Psychology 1981;35:58-62. [PubMed: 7248845] doi: $10.1037 / \mathrm{h} 0081127$.

Porac C, Coren S, Girgus J, Verde M. Visual-geometric illusions: Unisex phenomena. Perception 1979;8:401-412. [PubMed: 503771]

Prinzmetal W, Beck D. The tilt-constancy theory of visual illusions Journal of Experimental Psychology. Human Perception and Performance 2001;27:206-217. [PubMed: 11248934]doi: 10.1037/0096-1523.27.1.206.

Ring H, Woodbury-Smith M, Watson P, Wheelwright S, Baron-Cohen S. Clinical heterogeneity among people with high functioning autism spectrum conditions: Evidence favouring a continuous severity gradient. Behavioral and Brain Functions 2008;4:11. [PubMed: 18289376]doi: 10.1186/1744-9081-4-11.

Ropar D, Mitchell P. Are individuals with autism and Asperger's syndrome susceptible to visual illusions? Journal of Child Psychology and Psychiatry and Allied Disciplines 1999;40:1283-1293.doi: $10.1017 /$ S0021963099004667.

Ropar D, Mitchell P. Susceptibility to illusions and performance on visuospatial tasks in individuals with autism. Journal of Child Psychology and Psychiatry, and Allied Disciplines 2001;42:539-549.doi: 10.1017/S002196300100717X.

Shah A, Frith U. An islet of ability in autism: a research note. Journal of Child Psychology and Psychiatry, and Allied Disciplines 1983;24:613-620.doi: 10.1111/j.1469-7610.1983.tb 00137.x.

Shah A, Frith U. Why do autistic individuals show superior performance on the block design task? Journal of Child Psychology and Psychiatry, and Allied Disciplines 1993;34:1351-1364.doi: 10.1111/j.1469-7610.1993.tb02095.x.

Shimamura AP, Prinzmetal W. The mystery spot illusion and its relation to other visual illusions. Psychological Science 1999;10:501-507.doi: 10.1111/1467-9280.00196.

Titchener, EB. Qualitative experiments. Vol. vol. 1. London: MacMillian; 1901. Experimental psychology: A manual of laboratory practice.

Voyer D, Voyer S, Bryden MP. Magnitude of sex differences in spatial abilities-A meta-analysis and consideration of critical variables. Psychological Bulletin 1995;117:250-270. [PubMed: 7724690] doi: 10.1037/0033-2909.117.2.250. 
Wakabayashi A, Baron-Cohen S, Uchiyama T, Yoshida Y, Kuroda M, Wheelwright S. Empathizing and systemizing in adults with and without autism spectrum conditions: Cross-cultural stability. Journal of Autism and Developmental Disorders 2007;37:1823-1832. [PubMed: 17180457]doi: 10.1007/s10803-006-0316-6.

Wakabayashi A, Baron-Cohen S, Wheelwright S, Tojo Y. The autism-spectrum quotient (AQ) in Japan: A cross-cultural comparison. Journal of Autism and Developmental Disorders 2006;36:263-270. [PubMed: 16586157]doi: 10.1007/s10803-005-0061-2.

Weintraub DJ. Ebbinghaus illusion: Context, contour, and age influence the judged size of a circle amidst circles. Journal of Experimental Psychology, Human Perception and Performance 1979;5:353-364. [PubMed: 528945]doi: 10.1037/0096-1523.5.2.353.

Witkin HA, Asch SE. Studies in space perception. III. Perception of the upright in the absence of a visual field. Journal of Experimental Psychology 1948;38:603-614. [PubMed: 18885709]doi: 10.1037/h0055372.

Woodbury-Smith MR, Robinson J, Wheelwright S, Baron-Cohen S. Screening adults for Asperger Syndrome using the AQ: A preliminary study of its diagnostic validity in clinical practice. Journal of Autism and Developmental Disorders 2005;35:331-335. [PubMed: 16119474]doi: 10.1007/s10803-005-3300-7.

Wundt, W. Die geometrisch-optischen Taeuschungen [The geometric-optical illusion]. Leipzig: Teubner; 1898.

Zanuttini L. Figural and semantic factors in change in the Ebbinghaus illusion across four age groups of children. Perceptual and Motor Skills 1996;82:15-18. [PubMed: 8668469]

Zöllner F. Ueber eine neue Art von Pseudoskopie und ihre Beziehungen zu den von Plateau und Oppel beschriebenen Bewegungsphänomenen. Annalen der Physik 1860;186:500-523.doi: 10.1002/andp.18601860712. 

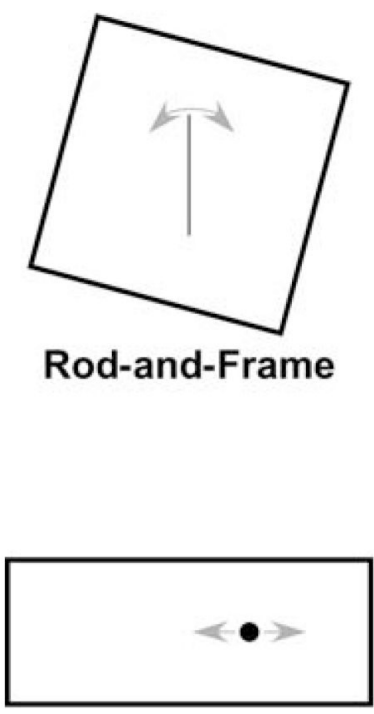

Roelofs

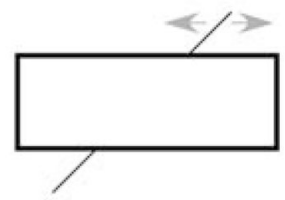

Poggendorff

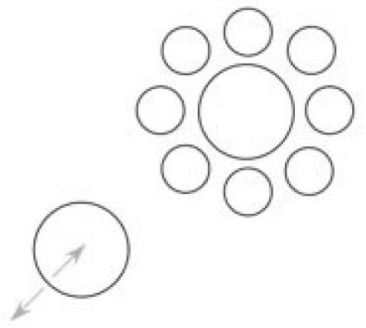

Ebbinghaus

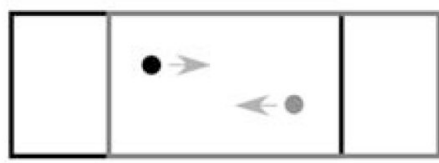

Induced Motion

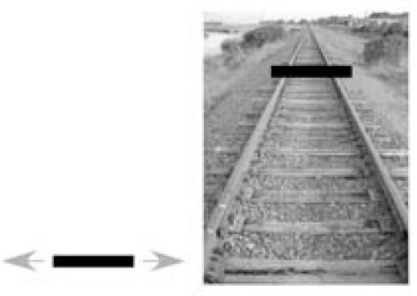

Ponzo

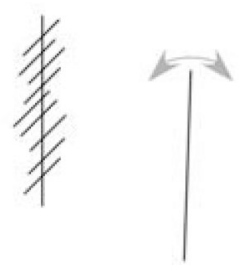

Zöllner

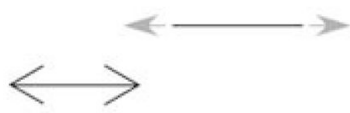

Müller-Lyer

Fig. 1.

Visual stimuli (not drawn to scale) used to test magnitude of susceptibilities in each of eight illusions, with gray arrows (not visible to participants) denoting the parameters (i.e., target location, orientation, length or size) under participant control 
Table 1

Results of factor analysis of illusion susceptibility

\begin{tabular}{|c|c|c|}
\hline Illusion & Susceptibility factor \#1 & Susceptibility factor \#2 \\
\hline Zöllner & 0.574 & 0.129 \\
\hline Roelofs & 0.557 & 0.130 \\
\hline Rod-and-frame & 0.555 & 0.144 \\
\hline Ponzo & 0.710 & -0.204 \\
\hline Poggendorff & 0.456 & -0.013 \\
\hline Ebbinghaus & 0.407 & 0.576 \\
\hline Müller-Lyer & 0.157 & 0.636 \\
\hline Induced motion & 0.294 & -0.700 \\
\hline
\end{tabular}

Bold values highlight loading weights that surpassed a threshold of \pm 0.4 
Table 2

Correlations (Spearman's rank correlation, $r_{\mathrm{s}}$ ) between illusion susceptibility factors and AQ, EQ and SQ

\begin{tabular}{lll}
\hline & Susceptibility factor \# $\mathbf{1}_{\text {mod }}$ & Susceptibility factor \# $\mathbf{2}_{\text {mod }}$ \\
\hline AQ & $r_{\mathrm{s}}=-0.107$ & $r_{\mathrm{s}}=0.021$ \\
& n.s. & n.s. \\
EQ & $r_{\mathrm{s}}=0.122$ & $r_{\mathrm{s}}=-0.153$ \\
& n.s. & n.s. \\
SQ & $\boldsymbol{r}_{\mathrm{s}}=\mathbf{- 0 . 3 3 8}$ & $r_{\mathrm{s}}=0.025$ \\
& $\boldsymbol{p}=\mathbf{0 . 0 0 0 1}$ & n.s. \\
\hline
\end{tabular}

